\title{
Four-dimensional magnetic resonance evaluation of valve preservation: Keep those studies flowing
}

\author{
T. Brett Reece, MD
}

\author{
From the Division of Cardiothoracic Surgery, Department of Surgery, University of Colorado School of Medicine, \\ Aurora, Colo. \\ Disclosures: Author has nothing to disclose with regard to commercial support. \\ Received for publication July 22, 2018; accepted for publication July 23, 2018; available ahead of print Oct 23, \\ 2018. \\ Address for reprints: T. Brett Reece, MD, 12631 E 17th Ave, Aurora, CO (E-mail: BRETT.REECE@ \\ UCDENVER.EDU). \\ J Thorac Cardiovasc Surg 2019;157:466 \\ $0022-5223 / \$ 36.00$ \\ Copyright (c) 2018 by The American Association for Thoracic Surgery \\ https://doi.org/10.1016/j.jtcvs.2018.07.102
}

In this issue of the Journal, Gaudino and colleagues ${ }^{1}$ present an excellent evaluation of differences in flow patterns across aortic root reconstruction techniques with and without neosinuses and compared them with normal native roots by using 4-dimensional magnetic resonance imaging. They were able to demonstrate preservation of flow dynamics within the root throughout systole. They were also able to demonstrate the sinusoidal conformation differences between the tube grafts and neosinus grafts to promote comparison.

Although I personally prefer the neosinus grafts in my own hands, the study acknowledges that these varied flow patterns have not demonstrated differences in long-term outcomes to date. Furthermore, there are proponents of the tube grafts who actually mold the tube into neosinuses, which they believe to provide them with added flexibility in tailoring the size and shape of the root to the patient size. This initial-30 patient evaluation is critical to beginning to evaluate more subtle differences, such as depth of implantation, sizes of grafts, and leaflet manipulation, in a technique that varies fairly widely among surgeons. The shape of the graft is an obvious starting point for these evaluations, but there are many more variations that can be evaluated for optimization of the procedure. Even the variations of the valve-preserving procedure, such as the Yacoub approach or even flexible or rigid annular stabilization, should be added to this functional evaluation. Many talented surgeons have demonstrated such variations, with admirable short-

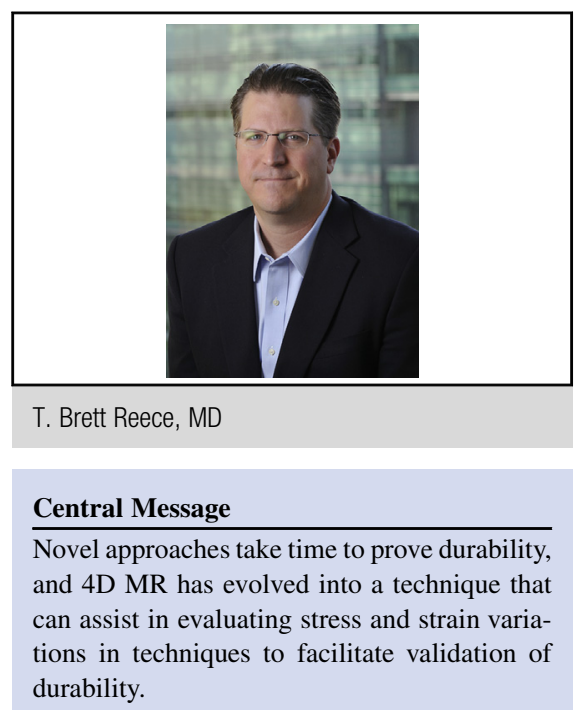

See Article page 455 .

term and midterm outcomes. We need more studies like these to tease out the subtle differences before they are defined by time, however, because our patients are the ones that will benefit most from this broadened understanding.

Although differences between preservation approaches were demonstrated by, the implications of these are far from understood. This is an excellent starting point for flow evaluations of different types of aortic reconstructions, but we all look forward to expanded analysis regarding the implications of these reconstructions on the leaflet stresses, the left ventricular work, and even the distal aortic wall stresses.

\section{Reference}

1. Gaudino M, Piatti F, Lau C, Sturla F, Weinsaft JW, Weltert L, et al. Aortic flow after valve sparing root replacement with or without neosinuses reconstruction. J Thorac Cardiovasc Surg. 2019;157:455-65. 